\title{
FORMAÇÃO JURÍDICA E NOVAS TECNOLOGIAS: RELATO DE UMA APRENDIZAGEM EXPERIENCIAL EM DIREITO
}

\author{
LEGAL TRAINING AND NEW TECHNOLOGIES: REPORTING \\ EXPERIENTIAL LEARNING IN LAW COURSE
}

\section{FORMACIÓN JURÍDICA Y NUEVAS TECNOLOGÍAS: INFORME DE APRENDIZAJE EXPERIENCIAL EN CURSO DE DERECHO}

\author{
Marina Feferbaum* \\ Stephane H. B. Lima**
}

1 Introdução. 2 As novas tecnologias e o perfil dos novos profissionais de Direito. 3 Teoria da aprendizagem experiencial como uma estratégia do ensino. 4 Relato da experiência vivenciada no Laboratório de Tecnologia - LabTech. 5 Conclusão. Referências.

\begin{abstract}
RESUMO
O objetivo deste artigo é investigar a contribuição do ensino experiencial no campo do ensino jurídico enquanto instrumento adequado à formação das competências identificadas como importantes aos novos profissionais de Direito. Variadas transformações tecnológicas estão sendo vivenciadas nas profissões jurídicas, com a crescente inserção da automação e da inteligência artificial no mercado de Direito. Nesse cenário, buscou-se identificar as competências necessárias a esses novos profissionais para, a partir da utilização da teoria da experiência de ensino, ser proposto um novo método de formação jurídica com base na aprendizagem experiencial do Direito. Foi utilizada, portanto, como metodologia, especialmente, a análise de

* Doutora (2016), Mestre (2009) e Graduada (2006) em Direito pela Pontifícia Universidade Católica de São Paulo (PUC SP). Coordena o Centro de Pesquisa e Ensino em Inovação - CEPI FGV Direito SP. Suas linhas de pesquisa abrangem direitos humanos e tecnologia, ensino jurídico brasileiro e métodos de ensino em Direito. Escola de Direito da Fundação Getúlio Vargas. São Paulo, SP, Brasil. E-mail: <marina.feferbaum@fgv. br>. https://orcid.org/0000-0002-5235-9969

** Doutoranda em Teoria do Estado pela Universidade de São Paulo. Mestre (2018) em Direito Constitucional pela Universidade Federal do Ceará e Graduada (2014) em Direito pela Universidade Federal do Ceará. Pesquisadora do Centro de Ensino e Pesquisa em Inovação - CEPI FGV Direito SP. Desenvolve pesquisas e atividades de ensino nas áreas de Ensino Jurídico, Metodologias participativas; Direitos Humanos Digitais; Educação Digital e Regulação. Universidade de São Paulo. São Paulo, SP, Brasil. E-mail: <stephanelima21@ gmail.com>. https://orcid.org/0000-0002-4045-8492
\end{abstract}


doutrina, de acordo com referenciais teóricos da Educação (Kolb e Moon), em consonância com conclusões de pesquisas jurídicas sobre o perfil dos novos profissionais de Direito (CEPI); então, idealizou-se uma nova disciplina para o curso de graduação da FGV Direito SP, cujos resultados foram avaliados e se encontram presentes neste artigo. Concluiu-se, por meio da análise dos diários de bordo produzidos pelos alunos ao longo do semestre e de observação, que o método utilizado foi importante para o desenvolvimento das competências identificadas como relevantes à formação dos novos profissionais de Direito, quais sejam: desenvolver a capacidade de apresentar soluções criativas e rápidas de problemas; trabalhar colaborativamente em grupos diversos; e idealizar, executar e conduzir novos projetos.

Palavras-chave: Ensino Experiencial. Metodologia de ensino jurídico. Novas competências. Direito e Tecnologia.

\begin{abstract}
The aim of this paper is to investigate the contribution of experiential learning in teaching in the field of legal education as an appropriate instrument for improving competences identified as fundamental for new legal professionals. Several technological changes are being experienced in legal professions, with increasing insertion for automation and artificial intelligence (AI) in the law market. In this scenario, identifying the skills needed by these new professionals was sought, so that, based on the experience of teaching theory, a new method of legal education focused on experiential learning in law was proposed. Therefore, for methodos, doctrine of analysis was used, based on the theoretical frameworks of education (Kolb and Moon), associated with conclusions from the profile of legal professionals on legal research in Centro de Ensino e Pesquisa em Inovação (CEPI) for designing a new discipline for the law course at Fundação Getúlio Vargas (FGV) Direito SP, whose results were evaluated and presented in this article. This study concluded, through participant observation and analysis of the logbooks produced during the semester, that the method used was important for developing competences identified as relevant for the creation of new legal professionals who, namely, present creative and agile problem solving, work together in diverse groups and construct, execute and lead new projects.
\end{abstract}

Keywords: Experiential Learning in Teaching. Methods of legal education. New skills. Law and Technology.

\title{
RESUMEN
}

El objetivo de este artículo es investigar la contribución de la enseñanza experiencial en el campo de la educación jurídica, como un instrumento apropiado para la formación de competencias identificadas como importantes para los nuevos profesionales del derecho. Se están experimentando varios cambios tecnológicos en las profesiones jurídicas, con la creciente inserción de la automatización y la inteligencia artificial en el mercado legal. En este 
escenario, buscamos identificar las habilidades que necesitan estos nuevos profesionales, de tal modo que, en base a la teoría de la experiencia docente, se propuso un nuevo método de educación jurídica basado en el aprendizaje experimental del derecho. Por lo tanto, como metodología, se utilizó el análisis de la doctrina, basado en los marcos teóricos de la educación (Kolb y Moon), combinado con conclusiones de la investigación jurídica sobre el perfil de los nuevos profesionales del derecho (CEPI), para luego la creación de una nueva disciplina para el curso de derecho de FGV Direito SP, cuyos resultados fueron evaluados y están presentes en este artículo. Se concluyó, a través de la observación y el análisis de los libros de registro producidos durante el semestre, que el método utilizado fue importante para el desarrollo de las competencias identificadas como relevantes para la formación de los nuevos profesionales del derecho, a saber: resolución de problemas presentes de forma creativa y ágil; trabajar en colaboración en diversos grupos; e idealizar, ejecutar y liderar nuevos proyectos.

Palabras clave: Enseñanza experiencial. Metodología de la educación jurídica. Nuevas habilidades. Derecho y tecnología.

\section{INTRODUÇÃO}

Este artigo aborda a utilização da teoria da aprendizagem experiencial como uma escolha metodológica inovadora que visa contribuir para a formação jurídica brasileira ante os desafios trazidos pela inserção das novas tecnologias no mercado jurídico.

Parte-se do pressuposto de que a era tecnológica contemporânea constitui um fator relevante em relação à formação de profissionais e às metodologias de ensino. Tendo que enfrentar cada vez mais questões envolvendo a tecnologia, os profissionais com essa formação tradicional não têm desenvolvido habilidades múltiplas e interdisciplinares para além do Direito, fundamentais para atuar em um mundo jurídico cada vez mais complexo. Ao não saber lidar com demandas envolvendo softwares, inteligência artificial e automação de serviços ou mesmo ofertar diretamente esses produtos, profissionais jurídicos estão perdendo espaço no mercado de trabalho, uma vez que algumas de suas atividades, por exemplo, o gerenciamento de grande contingente de processos, estão sendo executadas com destreza por profissionais de outras áreas, como engenheiros ${ }^{1}$.

Soma-se a essa problemática a importância de se ter habilidades interpessoais para trabalhar com diversos pares de distintas áreas, cada vez mais em equipe e cooperando para atingir um objetivo comum, bem como competências para o desenvolvimento de projetos. Essas habilidades não curriculares são o cerne do sucesso de um trabalho e de um profissional com plasticidade para circular entre muitas áreas (CENTRO DE ENSINO E PESQUISA EM INOVAÇÃO, 2018a).

Além da análise de doutrina, relativa ao novo perfil dos profissionais de Direito e das

1 Engenheiros já compõem a equipe multidisciplinar de algumas das maiores bancas de escritório de advocacia de São Paulo, como Lee, Brock, Camargo Advogados, conforme disponível já em seus próprios sites: http:// lbca.com.br/index.php/quem-somos/. Acesso em: 22 nov. 2018. 
mudanças da forma de prestação do serviço jurídico, fundamentadas em Susskind (2008) e Goodman (2016), também foram adotados como referencial teórico autores da Educação, como Kolb (1984) e Moon (2004), a fim de explorar uma forma de ensino que permitisse o desenvolvimento de tais competências almejadas.

Nesse contexto, o aprendizado experiencial, mais conhecido pelo seu termo em inglês experiential learning, foi visualizado enquanto uma importante ferramenta em sala de aula e nos processos de capacitação para os desafios atuais vivenciados pelos profissionais de Direito, por tomar a vivência do aluno como ponto de partida para o processo de aprendizado, propiciando, igualmente, o desenvolvimento de habilidades interpessoais.

Nessa forma de ensino, por meio de um processo ativo, a aprendizagem se dá na prática e na atividade de reflexão sobre a própria vivência para que, então, sejam desenvolvidas novas habilidades, novos conhecimentos e novas atitudes. Dessa maneira, a experiential learning, ou aprendizagem experimental, tem se constituído como base para um aprendizado efetivo e participativo do aluno, o qual é colocado em uma posição ativa e corresponsável pela construção do seu próprio saber.

A partir da teoria do ensino experiencial e utilizando-se das competências a ser desenvolvidas com os alunos como ponto de chegada, foi proposta uma nova disciplina para a graduação da FGV Direito SP, a de Laboratório de Tecnologia - LabTech, cujo objetivo foi aproximar os alunos de Direito do vocabulário tecnológico, permitindo que eles refletissem sobre o papel dos profissionais da área diante da utilização da tecnologia cada vez mais intensa em sua profissão. Para tanto, os estudantes foram convidados a elaborar, do início ao fim, auxiliado por professores e por uma empresa parceira de tecnologia, um projeto inovador de automação de documentos jurídicos.

Foi realizada a análise dos relatos de aprendizagem, no curso de um semestre, a fim de verificar os resultados do uso do ensino experiencial, combinada com outras estratégias que aproximavam os estudantes do uso da tecnologia no Direito. Ao final, constatou-se o benefício da utilização do método experiencial adotado, especialmente útil por promover nos alunos algumas das competências mapeadas como necessárias aos profissionais de Direito diante dos impactos causados por uma maior adoção de tecnologia no mundo jurídico atual, em especial o trabalho colaborativo em equipe.

Assim sendo, a estrutura deste artigo consiste em explorar, em um primeiro momento, as mudanças que as novas tecnologias trouxeram para os profissionais de Direito, especialmente quanto às competências mais requisitadas nesse contexto. Em seguida, buscou-se abordar os princípios que regem o ensino experiencial, a fim de que, ao final, fosse possível um relato de uma disciplina ofertada no âmbito da graduação da FGV Direito SP, que se propôs a utilizar uma estratégia de ensino experiencial para capacitar os estudantes a ofertar serviços jurídicos de uma forma diferenciada, avaliando, portanto, a adequação do método à formação dos graduandos no perfil identificado. 


\section{AS NOVAS TECNOLOGIAS E O PERFIL DOS NOVOS PROFISSIONAIS DE DIREITO}

O impacto da inserção da tecnologia na área de Direito pode ser interpretado de duas formas distintas: de um lado, o uso ostensivo das tecnologias traz questões nunca antes enfrentadas pelos profissionais de Direito, que necessitam desenvolver respostas rápidas e soluções criativas para problemas antes inexistentes; e, de outro, o uso de tecnologia para a prestação de serviços jurídicos modifica a forma como se deve capacitar os profissionais para sua atuação integral no mercado contemporâneo.

Para o objetivo proposto no artigo, o enfoque será no segundo impacto citado, ou seja, na forma como a tecnologia é capaz de alterar os requisitos para a formação dos profissionais de Direito ao modificar a própria forma de se prestar os serviços jurídicos. Isso será tratado com mais detalhes a seguir, a fim de visualizar os requisitos para a formação de novos profissionais nesse novo contexto.

Susskind (2008) escreveu um livro cujo tema central era descrever como advogados deveriam mudar a maneira que trabalhavam a partir do uso das ferramentas tecnológicas disponíveis, em razão da pressão existente por serviços jurídicos a baixo custo, impulsionados pela crise. O livro, chamado de, em tradução livre, "O fim do advogado? Repensando a natureza dos serviços jurídicos”, demonstra como, no mercado inglês, diversas transformações podem ser adotadas para aumentar a eficiência da prestação dos serviços jurídicos.

Quase dez anos depois, a mudança no mercado jurídico também começa a ser percebida no Brasil, sendo noticiadas nas grandes mídias variadas inovações por parte de empresas e setor público que visam transformar o modo como hoje se pratica o Direito no país.

No âmbito do sistema de justiça, observa-se a implementação de sistemas inteligentes que auxiliam os julgadores até mesmo em seu processo de decisão. Em novembro de 2018, no âmbito do TJMG, foi realizada uma sessão inédita em que, com apenas um clique no computador, foi julgado um total de 280 processos. E essa não é uma iniciativa isolada (MINAS GERAIS, 2018)

Os tribunais superiores também se movimentam em busca de adotar a tecnologia, de modo a acelerar o curso do processo. O sistema Victor, no âmbito do STF, que utiliza inteligência artificial, está sendo testado para ler todos os recursos extraordinários e identificar quais podem ser agregados em temas já fixados de repercussão geral (BRASIL, 2018).

A busca da eficiência por meio da inovação no setor público pode ser constatada também por iniciativas como a do TJPE, que divulgou, no dia 20 de novembro de 2018, que já utilizava sistema inteligente para o gerenciamento e a triagem de processos de execução fiscal, conseguindo identificar processos prescritos ou incorretamente distribuídos, reduzindo-se, em 18 meses, o trabalho que antes era realizado exclusivamente por servidores, que deveriam ser realocados para uma função de maior complexidade (PERNAMBUCO, 2018).

Não apenas os tribunais têm usado as novas ferramentas, mas também, principalmente, escritórios e departamentos jurídicos têm feito uso de diversas soluções oferecidas pelas mais 
de 100 startups hoje existentes no país que ofertam serviços tecnológicos ao mercado jurídico.

A Associação Brasileira de LawTech e LegalTechs é o órgão responsável por agregar as startups brasileiras ligadas à área jurídica. As empresas associadas se distinguem entre si, compondo diversas categorias diferentes, que vão desde aquelas que auxiliam os profissionais de Direito com plataforma de análise e compilação de dados, passando por empresas que criam e ofertam softwares de automação de documentos jurídicos, indo até plataformas que se dedicam à resolução on-line de conflitos por meio da mediação, arbitragem e negociação.

A AB2L possuía um total de 88 LegalTechs associadas em fevereiro de 2018, classificadas em nove grandes áreas de atuação. Em novembro do mesmo ano, já continha 136 LawTechs e LegalTechs, 33 escritórios de advocacia, 2 departamentos jurídicos e 24 prestadores de serviço, totalizando 195 associados (AB2L, 2018).

Observa-se, assim, que o número de startups que oferecem serviços a departamentos jurídicos e escritórios cresce exponencialmente, o que faz com que os produtos e os serviços tenham um preço mais atrativo. $\mathrm{O}$ alto mercado de competitividade do mundo jurídico gera uma necessidade de maior eficiência na entrega da prestação jurídica, de modo que, com a adoção da tecnologia - especialmente a automação e o aprendizado de máquinas -, é possível que os profissionais da área jurídica consigam produzir mais, em menos tempo, por um menor custo. Esse fenômeno já é visualizado também em outros mercados há algum tempo. (GOODMAN, 2016)

A partir desse panorama de mudanças, o projeto de pesquisa "Tecnologia, Profissões e Ensino Jurídico", desenvolvido pelo Centro de Ensino e Pesquisa em Inovação da FGV Direito SP, buscou identificar, entre os anos de 2017 e 2018, de que maneiras as tecnologias computacionais associadas à inteligência artificial alteravam as profissões jurídicas, transformando e reorganizando as funções e as atividades realizadas por profissionais do setor, e como esse processo impactava na formação em Direito no Brasil. Nos relatórios da pesquisa, confirmou-se que há um movimento de mudanças que impactarão significativamente o modus operandi dos profissionais dessa área, especialmente daqueles em início de carreiras e com funções mais mecânicas.

$\mathrm{Na}$ parte quantitativa da pesquisa, por meio de questionários direcionados a escritórios de advocacia de todo o território nacional, foi possível constatar que, muito embora a tecnologia ainda não esteja sendo ostensivamente utilizada em ampla escala no Brasil, ficando restrita aos escritórios de maior porte: "Há amplo espaço para implementação de ferramentas tecnológicas avançadas, diante dos indícios de alta repetitividade dos trabalhos, que se verificam na presença frequente do contencioso de massa entre as atividades dos escritórios e no uso disseminado de modelos."(CENTRO DE ENSINO E PESQUISA EM INOVAÇÃO, 2018b, p. 11).

$\mathrm{Na}$ parte qualitativa da pesquisa, extraída da análise de entrevistas coletadas de diversos agentes ligados à transformação tecnológica no mundo jurídico, como advogados de departamento jurídico, sócios de escritórios, proprietários de startups, entre outros, foi verificado que a substitui- 
ção de profissionais por máquinas se encontra concentrada em cargos de hierarquia mais baixa, bem como se notou um movimento de incorporação de profissionais sem formação jurídica às organizações jurídicas, como engenheiros e cientistas da programação; por fim, contatou-se um esforço para incorporar novas tecnologias integradas na elaboração e prestação de serviços jurídicos (CENTRO DE ENSINO E PESQUISA EM INOVAÇÃO, 2018a).

Para responder à questão "Como preparar os profissionais de Direito para tais transformações?", foram mapeadas as novas funções, habilidades e competências esperadas dos profissionais dessa área dentro desse novo contexto.

Como há uma tendência de que o escritório de advocacia não seja mais aquele espaço reservado apenas a advogados, mas sim um ambiente em que soluções são construídas em conjuntos entre profissionais de Direito e de tecnologia de informação, verificou-se a necessidade de ser desenvolvida uma nova competência aos graduandos: a capacidade de diálogo e construção coletiva de soluções entre áreas diferentes.

Para que isso aconteça, por vezes, podem ser necessários também conhecimentos gerais dos estudantes de Direito sobre programação e linguagens de computação para que seja produtivo o trabalho, facilitando a comunicação entre os profissionais das diferentes áreas.

A necessidade de saber como trabalhar em equipes multidisciplinares também foi constatada como um ponto central essencial para o desenvolvimento dos alunos dentro dessa nova realidade, conforme comentário a seguir de um dos entrevistados da pesquisa:

\footnotetext{
É que a partir do momento que existe uma necessidade tecnológica operacional, existe um trabalho conjunto e com muita sinergia entre a nossa parte tecnológica e nosso advogado, para que a gente consiga integrar exatamente essas duas possibilidades na feitura de uma solução tecnológica, de uma aplicação, que efetivamente seja feita de acordo com o nosso dia a dia, porque o nosso operacional está ali e é advogado, e está vendo, e ao mesmo tempo a nossa área tecnológica consiga desenvolver sem precisar muito tempo de maturação dessa ideia, tendo em vista que ele tem o apoio de um advogado, que ele sabe o trâmite e conhece o dia a dia do operacional da empresa (CENTRO DE ENSINO E PESQUISA EM INOVAÇÃO, 2018a, p. 35).
}

Por mais que o trabalho em equipe e a elaboração de projetos em grupo sejam algo já considerado importante para a formação jurídica, o uso da tecnologia na prestação de serviços jurídicos parece o condão de aprofundar ainda mais tal exigência.

A partir dessas observações, levantou-se a hipótese de que a abordagem passiva e exclusivamente doutrinária dos métodos de ensino em massa não abriria espaço para questionamentos, construções de saberes ou, ao menos, reflexão sobre o papel dos profissionais de Direito nesse mundo mediado pelo âmbito tecnológico, muito menos para que estes possam ser capacitados para o bom trabalho em equipe.

A metodologia expositiva não parecia o meio mais adequado para capacitar os aprendizes nas demais competências necessárias identificadas, nas quais se destacam: a resolução 
de problemas de modo veloz e criativo; a competência para o trabalho colaborativo, inclusive com profissionais de outras áreas; e a elaboração e a condução de projetos.

Procurou-se, então, uma alternativa para a metodologia de ensino nos cursos de Direito, utilizando-se da teoria da aprendizagem experiencial como base, a fim de, por meio de uma experiência concreta, durante um semestre, identificar se esse método seria apto a conduzir à transformação necessária do ensino de Direito no país, nos termos explorados. A seguir, foram verificados, portanto, os fundamentos da teoria da aprendizagem experiencial e como ela foi incorporada à formação jurídica por meio da criação de uma nova disciplina na graduação da FGV Direito SP.

\section{TEORIA DA APRENDIZAGEM EXPERIENCIAL COMO ESTRATÉGIA DE ENSINO}

A teoria da aprendizagem experiencial, também chamada de experiential learning theory (ELT) ou simplesmente experiential learning, é definida por Kolb (1984, p. 41) como "o processo no qual o conhecimento é criado por meio da transformação da experiência. O conhecimento resulta da combinação de capturar e transformar a experiência”².

A ELT é considerada uma teoria holística por integrar aspectos da experiência, da percepção, da cognição e do comportamento. Além disso, não é definida pelos resultados apresentados, senão como um processo contínuo de aprender e reaprender, requerendo a resolução dialética integral (pensamento, sentimento, percepção e comportamento) de conflitos para adaptação ao mundo, interação das pessoas com o meio ambiente e construção de conhecimento (KOLB, 1984).

Logo, a ELT considera o aluno e suas experiências como centrais para a construção do conhecimento, cujo resultado é um processo ativo por parte do aprendiz e refletido em mudanças de conceitos e de comportamentos. Isso porque as experiências concretas são a base para observações e reflexões, as quais são assimiladas e transformadas em conceitos abstratos a partir dos quais novas implicações podem ser delineadas e, assim, modificar o comportamento. Essas implicações podem ser testadas e servir de guia para a criação de novo repertório de experiências.

Sob essa perspectiva, a relação entre professores e alunos não é mais vista como vertical, mas forma uma espécie de grupo de trabalho em que o posicionamento dos estudantes deixa de ser meramente passivo. O vínculo entre todos os participantes envolvidos e o papel dos docentes ou instrutores muda radicalmente, pois, de detentores e transmissores de saber, passam a ser facilitadores do aprendizado, em uma relação horizontal e coletiva, enquanto os discentes passam a desenvolver uma relação cooperativa com seus pares, configurando uma equipe empenhada em determinado objetivo, e não mais passivos nem concorrentes ou justapostos para receber um produto final.

Para Moon (2004, p. 165), a experiential learning difere do ensino convencional acadêmi-

2 Tradução dos autores: "The process whereby knowledge is created through the transformation of experience. Knowledge results from the combination of grasping and transforming experience" (KOLB, 1984). 
co justamente porque os alunos gerenciam seu próprio aprendizado, em vez de seguirem as orientações dos professores sobre o que fazer e quando fazer. Logo, a relação entre ambos é diferente, uma vez que os docentes delegam muitas responsabilidades aos discentes. Além disso, o aprendizado não se limita à sala de aula, a conteúdos curriculares ou a textos acadêmicos, mas ele se dá quando os aprendizes precisam identificar os conhecimentos que adquiriram, refletindo sobre a própria trajetória conforme ela vai sendo construída.

Para tanto, se os professores não considerarem no processo de aprendizagem o histórico dos alunos, a realidade em que eles vivem, as experiências que eles já tiveram e todo seu repertório, o sucesso em tornar um conteúdo significativo e fazer com que as pessoas considerem outros pontos de vistas, mudando seus conceitos e suas atitudes, não se dará.

Quando aplicadas essas ações, o resultado combina experiência social e pessoal, da qual deriva a visão de mundo e sua atuação. Com base nessas premissas, várias técnicas podem ser empregadas para que os alunos vivenciem uma questão, reflitam, desenvolvam habilidades, construam ativamente seu conhecimento e modifiquem pensamentos e atitudes.

Nessa metodologia, o processo é tão importante quanto o resultado atingido. Por essa razão, a ELT também envolve elementos de avaliação ou autoavaliação do processo como um todo, que também podem se dar de diversas formas. Há vários recursos e técnicas grupais que facilitam a promoção da discussão e reflexões, com etapas e materiais simples, que foram utilizados na disciplina cujo relato se encontra descrito na última parte deste artigo.

A aprendizagem compreendida pela ótica da experiential learning define o processo de aprendizado em quatro etapas, com base em um ciclo de aprendizado, o que permite entender tanto as diferenças individuais quanto o tipo de aprendizagem. Tal ciclo é composto da experiência concreta, que é o pilar para a observação reflexiva e consequente conceituação abstrata, que conduz, por fim, à experimentação ativa.

Figura 1 - Produzido pelos autores

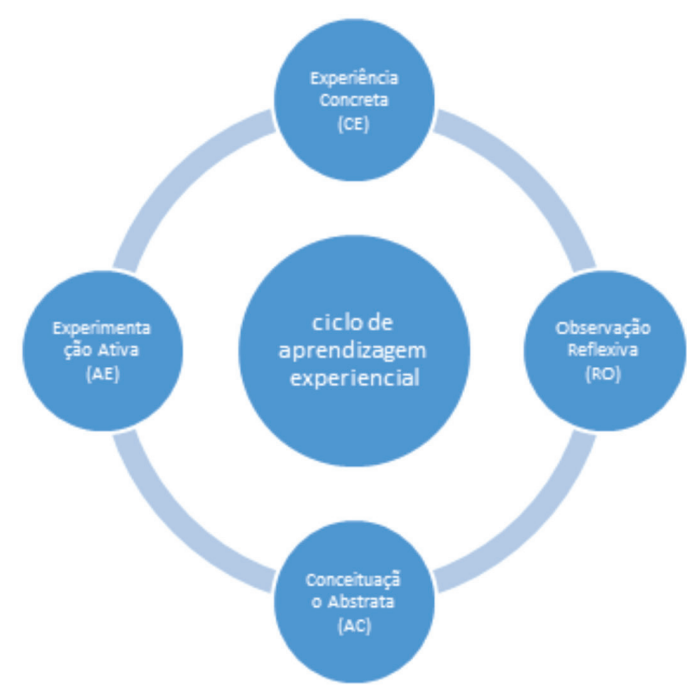

Fonte: adaptado de Kolb (1984). 
Dessa forma, no processo de aprendizagem, os alunos passam pela fase da experiência concreta (CE), na qual se envolvem completamente em novas experiências; na observação reflexiva $(\mathrm{RO})$, eles observam suas experiências e refletem a partir de outras perspectivas; na conceituação abstrata (AC), podem criar novos conceitos, integrando de modo lógico suas observações; por fim, na experimentação ativa (AE), já são capazes de usar esse novo repertório para tomar decisões e resolver problemas, testando suas teorias.

Nesse sentido, ao colocar os alunos como protagonistas da construção de seu próprio aprendizado, também é possível definir o sucesso do processo de aprendizagem da experiential learning pelas qualidades que são transmitidas aos aprendizes.

Moon (2004, p. 163) afirma que é possível observar nessas pessoas uma disposição para reorganizar ou alterar suas concepções anteriores sobre determinados temas. Elas também pensam por si próprias e são capazes de justificar muito bem seus posicionamentos, além de ter clareza do propósito das tarefas que realizam e das habilidades de autogerenciamento necessárias para trabalhar sozinhas ou em grupo. Essas pessoas também se tornam conscientes do seu modo de ser, ao mesmo tempo que mantêm a mente aberta e, por isso, conseguem trabalhar com indivíduos de diferentes visões. Por fim, são incentivadas a estar no controle de si mesmas, aprendendo a identificar o papel da emoção em seu aprendizado e a refletir sobre como chegaram ao seu conhecimento.

Considerar os alunos como centrais e ativos na construção de seu próprio aprendizado pressupõe uma postura crítica em relação a si próprios, a seus pares e ao seu entorno. Por isso, na experiential learning essa corresponsabilização envolve também o aspecto da avaliação. Avaliar significa dar valor, e, ao fazer isso, os estudantes têm a chance de reconhecer-se durante o processo de aprendizado, implicando-se e responsabilizando-se ainda mais durante todas as etapas, bem como dando sentido às suas ações e ressignificando seus valores (GHIRARDI, 2014).

Nessa proposta metodológica, os alunos devem ter voz e ser envolvidos nos processos de avaliação, bem como necessitam refletir sobre acontecimentos críticos durante a experiência realizada.

É possivel que o professor ou facilitador peça para que os alunos realizem uma apresentação sobre seus aprendizados após a vivência, elaborem um projeto para desenvolver novas ideias partindo da experiência obtida, realizem uma autoavaliação e/ou avaliação em grupo sobre o desempenho na tarefa proposta, sem que uma alternativa seja excludente das demais, já que todas avaliam uma dimensão diferente da aprendizagem.

O protagonismo dos alunos também pode envolver os processos de criação e seleção dos itens a que eles próprios serão submetidos e os critérios de avaliação da atividade, constituindo um exercício intenso acerca de objetivos, resultados e valores imparciais. Além disso, o professor pode aplicar uma rubrica de avaliação, como checklist, checagem de expectativas e outros tópicos que achar relevante para obter feedback de todo o processo.

Moon (2004, p. 166) cita vários exemplos para auxiliar os alunos a focalizar seu aprendizado enquanto elaboram um instrumento ou critérios para avaliar os resultados, indo desde manter um 
jornal ou portfólio sobre o aprendizado até elaborar um projeto para desenvolver ideias futuras ou mesmo fazer uma autoavaliação da tarefa realizada. Todos esses itens são apenas alguns exemplos de como essa importante etapa do ciclo de aprendizado pode ser conduzida coerentemente com o lugar que o aluno deve ocupar segundo a aprendizagem experiencial.

Conhecendo as características desse método de ensino e suas principais formas de avaliação, utilizou-se desta proposta para compor a metodologia de uma disciplina optativa no curso de graduação da FGV Direito SP, a fim de formar profissionais que estivessem mais capacitados a lidar com ferramentas de automação de documentos jurídicos, ao mesmo tempo que refletiam sobre as mudanças nas profissões jurídicas ocasionadas a partir do uso dessas novas tecnologias, justificando o uso do experiential learning combinado com outros métodos de ensino, de modo a buscar desenvolver nos estudantes a apropriação de um vocabulário tecnológico, a capacitação para elaboração de projetos, o fortalecimento do trabalho em equipe, entre outros.

Apresenta-se, então, um breve relato da disciplina denominada Laboratório de Tecnologia - LabTech, ministrada no âmbito da graduação da FGV Direito SP, e seus resultados, de modo a verificar sua contribuição para o desenvolvimento das competências identificadas como importantes no contexto das mudanças das prestações dos serviços jurídicos em virtude do aprofundamento do uso das novas tecnologias.

\section{RELATO DA EXPERIÊNCIA VIVENCIADA NO LABORATÓRIO DE TECNOLOGIA - LABTECH}

O aprendizado com base na experiência pode se dar de diversas formas dentro do curso de Direito, por meio de investigações de campo, simulações, role playing, dentre outros. O que há de comum é a apresentação de teoria e processos essenciais por intermédio da associação entre o conteúdo das aulas e as experiências pessoais dos alunos e da realidade em que vivem. Isso necessita ser utilizado pelo professor para gerar oportunidades de reflexão para que os próprios alunos estabeleçam uma ligação entre o aprendizado e suas interações com o mundo, inclusive a partir de elementos de fora da sala de aula.

Apesar da variedade de formatos possíveis e de objetivos, de modo geral a aprendizagem experiencial manifesta-se nos alunos em uma experiência e provoca reflexões sobre o que está sendo vivenciado, para que sejam desenvolvidas novas habilidades, novos conhecimentos, novas atitudes e novos modos de se pensar (MCGILL UNIVERSITY, 2014).

Cumpre ressaltar que o experiential learning não é um método que pode ser aplicado de forma dissociada à uma reflexão sobre a própria estrutura da condução da disciplina e dos temas vivenciados em sala de aula. Não existe um modelo enrijecido a ser aplicado. Assim sendo, não basta que haja mudança de postura dos docentes, mas é necessário que a elaboração de conceitos abstratos parta, de fato, da vivência dos estudantes, a qual poderá ser estimulada de diferentes formas pelos professores.

No âmbito da graduação da FGV Direito SP, optou-se pelo ensino vivencial ao se criar 
uma disciplina optativa denominada Laboratório de Tecnologia - LabTech, de 90 horas, com 15 encontros semanais, cujo foco era prover aos alunos a experiência de trabalhar desenvolvendo, em conjunto com uma empresa parceira, um projeto de tecnologia que tivesse o condão de alterar a forma como as atividades jurídicas estão sendo desempenhadas.

Os objetivos esperados foram: (i) familiarizar os alunos da FGV Direito SP em uma gramática tecnológica; (ii) capacitá-los para desenvolver em grupo um projeto tecnológico, que variará a cada edição; (iii) induzi-los a uma reflexão sobre a complexidade do trabalho em grupo e da comunicação interna para o desenvolvimento de projetos; (iv) aprimorar as habilidades de monitoramento de atividades em grupo e da comunicação não violenta entre seus membros; (v) capacitá-los para apresentações curtas, diretas e consistentes a respeito do seu projeto; e (vi) desenvolver uma forma de pensar com base em experimentações e prototipagem de processos e produtos (CENTRO DE ENSINO E PESQUISA EM INOVAÇÃO, 2019).

A ideia também foi permitir que o aluno vivenciasse a relação entre Direito e tecnologia, por meio do uso de ferramentas que necessitassem da linguagem de programação e do desenvolvimento do raciocínio lógico-jurídico, permitindo que a máquina pudesse "se apropriar da linguagem jurídica". Além disso, todas as dinâmicas que foram promovidas visavam desenvolver uma reflexão sobre a forma de condução dos trabalhos dos estudantes e os desafios enfrentados, inclusive no âmbito de relacionamento interpessoal entre os membros da mesma equipe.

Todo o processo foi mediado por práticas experienciais que, por meio de variadas dinâmicas de grupos propostas ao longo de todo o semestre, visavam permitir que o trabalho colaborativo, tanto entre os próprios alunos como entre eles e a empresa parceira de tecnologia, ocorresse de modo saudável e produtivo.

As dinâmicas tinham o condão de treinar a capacidade de escuta ativa dos estudantes e de empatia com as ideias dos demais. Também, em momento apropriado, os alunos tiveram a oportunidade de fazer uma autoavaliação e de dar feedbacks de modo construtivo aos integrantes do grupo de trabalho. A maneira como as dinâmicas foram conduzidas pressuponha sempre a experiência dos estudantes e seu protagonismo, abrindo espaço para que se colocassem perante o grupo, tal como demanda o ensino experiencial.

O projeto de tecnologia que norteou a iniciativa, em sua primeira edição, em 2017, foi enfocado em automação de documentos jurídicos, desenvolvido em parceria com a startup Looplex, que é uma plataforma brasileira de transformação digital de conteúdo, responsável pela automatização de documentos jurídicos em plataforma própria, com linguagem computacional adaptada aos advogados (Lawtex).

As tecnologias de automação de documentos fazem uso de ferramentas computacionais para a criação de documentos, auxiliadas ou não por humanos. Não se trata de uma ferramenta de autocompletar, mas, realmente, permite ao usuário, por meio de cliques, gerar em segundos o documento desejado adaptado às suas necessidades.

Os alunos precisaram aprender como identificar um documento jurídico passível de automatização e utilizar linguagem computacional, com a ajuda da empresa parceira, para 
criação de seus próprios templates.

Percebeu-se, por meio de observação, que isso auxiliou no desenvolvimento de uma competência essencial aos novos profissionais, que foi o de saber compreender elementos da linguagem própria da tecnologia, muito embora fosse percebida certa dificuldade inicial dos alunos em lidar com termos técnicos de outras áreas.

Além disso, os estudantes necessitaram pesquisar a fim de prever todas as nuances de determinada petição jurídica e pensar em como incluí-las em uma linguagem de programação que permitisse aos usuários leigos facilmente manejar a ferramenta elaborando seus próprios documentos jurídicos. Isso possibilitou que os estudantes trabalhassem a própria habilidade de argumentação jurídica, fortalecendo sua capacidade de antever cenários e argumentos para a construção de modelos de petições, competência que não tinha sido inicialmente antecipada, mas que, durante o curso da atividade, foi constatada sua importante para a elaboração das atividades demandadas.

No tocante à avaliação dos alunos, ela foi realizada por intermédio da agregação de variados parâmetros hábeis a valorar o engajamento dos participantes nas atividades experienciais e os demais objetivos elencados. Assim, valorou-se a participação em sala de aula, uma vez que cada aluno recebeu uma nota de participação proporcional à sua contribuição durante as discussões, os debates e as atividades.

Além disso, incentivou-se o engajamento fora da sala de aula, o que foi acompanhado por meio de diários de atividades (diário de bordo). No início da disciplina, os alunos foram instruídos a manter diários de atividade durante toda a disciplina, nos quais relataram o desenvolvimento de seus projetos, assim como as dificuldades enfrentadas ao longo do processo. Os diários foram entregues mensalmente para que os professores pudessem avaliar a progressão dos alunos durante as experiências proporcionadas pelo curso e foram mantidos em anonimato.

Adicionalmente, foi realizada a avaliação final do produto. Durante o evento de finalização do curso, professores pré-selecionados avaliaram o produto criado pelos alunos, atribuindo uma nota. A avaliação em pares também foi um diferencial, já que os estudantes foram convidados a atribuir uma nota aos demais de sua equipe de trabalho, abrindo espaço para discussões frutíferas sobre as nuances do trabalho em equipe e constatando-se suas diversas dificuldades quanto a esse ponto. Por fim, foi avaliada a apresentação final do grupo no dia do evento, quando os alunos se expuseram para uma plateia de forma concisa, direta e objetiva.

Destacou-se o resultado do diário de atividades, uma vez que foi possível o acompanhamento de todo o processo experiencial vivenciado ao longo das descobertas e dos trabalhos que estavam sendo realizados, constatando-se a mudança de mentalidade dos estudantes quanto aos impactos da tecnologia no mercado jurídico e ao papel do advogado em conduzir tal transformação, bem como as dificuldades enfrentadas no manejo do uso da linguagem de programação e no trabalho em equipe.

No tocante à metodologia de ensino em sala de aula, foram utilizadas, principalmente, técnicas de ensino experiencial, além de outras técnicas de aprendizagem com base em pro- 
jetos, tendo sido dividida a disciplina em três arcos de aprendizagem:

(I) capacitação tecnológica, na qual os alunos tiveram ciclos formativos com a empresa parceira do projeto. Nesta etapa, também foram trabalhados temas como formação de grupo e discutidos de que maneira seria a dinâmica dos fluxos de trabalho, mediante o uso de ferramentas vivenciais;

(I) dinâmicas de reflexão e aprendizagem, em que foram realizadas dinâmicas de integração, sensibilização, prototipagem, validação, feedback positivo, entre outras. Esta etapa foi mais vinculada ao tipo de aprendizagem experiencial descrita; e

(III) testes e validações, nos quais foram realizadas atividades de validação do código criado pelos alunos, os quais tiveram a oportunidade de sair da sala de aula para ir até o ambiente da empresa parceira, além de falar com outros profissionais de seu interesse para a validação dos trabalhos que estavam sendo desenvolvidos.

Ao final da disciplina, os alunos conseguiram entregar, com êxito, como produto: dois contratos automatizados, um de locação de espaço em shopping center e outro social de sociedade limitada; e duas petições, uma administrativa, de oposição de registro de marca junto ao INPI, e outra judicial, de repetição de indébito no âmbito do ICMS. Esses produtos foram apresentados a variados convidados em evento aberto ao final do semestre.

Como resultado, foi possível, com essa nova disciplina, transmitir muito mais do que apenas o conteúdo; houve, principalmente, o desenvolvimento de, pelo menos, duas das competências mapeadas como essenciais aos novos profissionais de Direito, quais sejam:

a) o fortalecimento da habilidade de tradução de uma linguagem jurídica para uma linguagem tecnológica, permitindo uma facilidade de comunicação dos alunos com os profissionais da área de tecnologia e;

b) a melhoria do trabalho colaborativo em grupos, o que pode estar relacionado a variadas atividades experienciais que visavam praticar a capacidade de escuta ativa dos participantes, os quais treinavam aspectos de liderança e de comunicação entre pares.

Além de todos esses benefícios, os estudantes ainda foram capacitados a prestar o serviço jurídico de modo diferenciado, a partir do uso consciente da tecnologia existente ${ }^{3}$.

\section{CONCLUSÃO}

Percebeu-se um impacto relativo às alterações na forma como o serviço jurídico é prestado por meio do uso de tecnologias como a automação e o aprendizado de máquinas, o

3 O relato detalhado da disciplina em todas as suas edições, bem como de outras disciplinas voltadas também à melhoria da qualidade de formação dos profissionais de Direito ante as transformações digitais, pode ser encontrado no trecho pertinente ao relatório de ensino da pesquisa "Tecnologia, Profissões e Ensino Jurídico", realizado pelo Centro de Ensino e Pesquisa em Inovação. Disponível em: https://www.academia.edu/39307191/Relat\%C3\%B3rio_das_Iniciativas_de_ Ensino_-_Projeto_TECNOLOGIA_PROFISS\%C3\%95ES_E_ENSINO_JUR\% $\bar{C} 3 \% 8 \mathrm{DDICO}$ _. 
que exige o aprimoramento de novas competências dos profissionais de Direito para os que desejem trabalhar em áreas de grande inserção tecnológica. Constatou-se que o profissional de Direito, nos dias atuais, precisa aprender a trabalhar em equipes multidisciplinares, com profissionais de outras áreas, e a se apropriar, além da lógica jurídica, da lógica de programação para construir mais facilmente soluções em cooperação com os profissionais de outras áreas.

Observou-se que, agora, com a utilização de big datas, inteligência artificial, linguagem de programação e softwares para realizar serviços jurídicos, a necessidade de se desenvolver competência, em vez de apenas se propor a transmissão de conteúdos, está ainda mais acelerada, abrindo espaço para a utilização de uma metodologia mais experiencial em sala de aula, capaz de despertar nos estudantes a participação no processo de aprendizagem de modo integral.

O experiential learning permite que, de modo colaborativo, por meio de um processo de relacionamento significativo entre os participantes das experiências, haja uma transformação da mentalidade dos estudantes, fazendo-os se apropriarem de conhecimentos e competências sólidas a partir das próprias reflexões das experiências facilitadas em salas de aula pelos professores. Infelizmente, apesar das vantagens significativas, esse método ainda é pouco conhecido no Brasil, principalmente pelas universidades, não sendo comumente utilizado em sala de aula.

Nesse sentido, utilizou-se do experiential learning como uma das bases da metodologia de ensino de uma disciplina optativa do curso de graduação da FGV Direito SP, a fim de se repensar o processo de aprendizado, os papéis do aluno e do docente e todas as implicações envolvidas na tarefa de transformar-se para transformar, logrando-se êxito no desenvolvimento de variadas competências descritas como essenciais aos novos profissionais. Ainda, a disciplina fez com que os alunos refletissem sobre a mudança do papel dos profissionais de Direito ante, especificamente, as tecnologias de automação.

Apesar dos resultados positivos, com a consequente incorporação do projeto de modo permanente na grade curricular do curso de Direito, foi possível perceber algumas dificuldades nos estudantes para o desenvolvimento das competências almejadas.

Por meio da análise do diário de bordo, notou-se certa resistência dos alunos em aprender a lidar com o vocabulário tecnológico, o que foi percebido como superado rapidamente ao longo do curso, não só pelos comentários deles próprios, mas também pelos produtos finais bem-sucedidos entregues. Já uma segunda dificuldade não antecipada foi relativa ao trabalho em equipe, constatando-se, ao longo do semestre, falhas na comunicação entre membros, desigualdade na atribuição de tarefas e dificuldades na realização de cobranças. Durante todo o processo isso foi trabalhado dentro das dinâmicas vivenciais que exploraram a importância da liderança compartilhada e da boa comunicação para o trabalho em equipe, demonstrando que um espaço seguro, acolhedor e agradável é essencial para desenvolver tais competências dos profissionais jurídicos. Ao final, por meio da escuta dos estudantes, foi percebido que eles estavam mais conscientes dos desafios do trabalho em grupo, bem como pensavam autonomamente em como mitigá-los.

Espera-se que esta iniciativa descrita brevemente seja incentivo para a criação de outras 
propostas de ensino inovadoras que também utilizem métodos experienciais para promover, nos estudantes, a adequação necessária para que estes se tornem os profissionais que o futuro espera.

\section{REFERÊNCIAS}

AB2L. Radar de Lawtechs e Legaltechs. 2018. Disponível em: https://www.ab2l.org.br/ radar-lawtechs/. Acesso em: 23 nov. 2018.

BARREAU QUEBEC. Hourly Billing Time for A Rethink. Summary report adopted by the Barreau Du Quebec's Board of Directors., Barreau Du Quebec, 2016

BRASIL. Conselho Nacional de Educação. Câmara de Educação Superior. Resolução no 9, de 29 de setembro de 2004. Institui as Diretrizes Curriculares Nacionais do Curso de Graduação em Direito e dá outras providências. Diário Oficial da União, Brasília, DF, 1 out. 2004. Disponível em: http://portal.mec.gov.br/cne/arquivos/pdf/rces09_04.pdf. Acesso em: 12 jan. 2018.

BRASIL. Conselho Nacional de Educação. Câmara de Educação Superior. Resolução no 5, de 18 de dezembro de 2018. Institui as Diretrizes Curriculares Nacionais do Curso de Graduação em Direito e dá outras providências. Diário Oficial da União, Brasília, DF, 18 dez. 2019. Disponível em: http://portal.mec.gov.br/index.php?option=com_docman\&vie w=download\&alias=104111-rces005-18\& category_slug=dezembro-2018-pdf\&Itemid=30192. Acesso em: 12 fev. 2018.

BRASIL. Supremo Tribunal federal. Inteligência artificial vai agilizar a tramitação de processos no STF. 2018. Disponível em http://www.stf.jus.br/portal/cms/verNoticiaDetalhe.asp?idConteudo=380038. Acesso em: 23 nov. 2018.

CENTRO DE ENSINO E PESQUISA EM INOVAÇÃO (CEPI). O futuro das profissões jurídicas: você está preparad@?. Sumário executivo da pesquisa qualitativa "tecnologia, profissões e ensino jurídico”. FGV DIREITO SP, São Paulo, 2018a. Disponível em: https://direitosp.fgv.br/sites/direitosp.fgv.br/files/arquivos/cepi_futuro_profissoes_juridicas_quali_v4.pdf. Acesso em: 22 jan. 2019.

CENTRO DE ENSINO E PESQUISA EM INOVAÇÃO (CEPI). O futuro das profissões jurídicas: você está preparad@?. Sumário executivo da pesquisa quantitativa "tecnologia, profissões e ensino jurídico”. FGV DIREITO SP, São Paulo, 2018b. Disponível em: https://direitosp.fgv.br/sites/direitosp.fgv.br/files/arquivos/cepi_futuro_profissoes_juridicas_quanti_v5.pdf. Acesso em: 22 jan. 2019.

CENTRO DE ENSINO E PESQUISA EM INOVAÇÃO (CEPI). O futuro das profissões jurídicas: você está preparad@?. Sumário executivo das iniciativas de ensino "tecnologia, profissões e ensino jurídico”. FGV DIREITO SP, São Paulo, 2019. Disponível em: https://www.academia.edu/39307191/Relat\%C3\%B3rio_das_Iniciativas_de_Ensino_-_Pro- 
jeto_TECNOLOGIA_PROFISS\%C3\%95ES_E_ENSINO_JUR\%C3\%8DDICO_.Acesso em: 19 set. 2019.

GHIRARDI, Garcez. O instante do encontro: questões fundamentais para o ensino jurídico. São Paulo: FGV, 2014.

GOODMAN, Joanna. Robots in Law: how artificial intelligence is transforming legal services. London: ARK Group, 2016.

KOLB, David. A. Experiential learning: experience as the source of learning and development. Englewood Cliffs, NJ: Prentice Hall, 1984.

MCGILL UNIVERSITY. Guidelines for assessment of experiential learning. Montreal: Teaching and Learning Services, 2014.

MINAS GERAIS. Tribunal de Justiça de Minas Gerais. TJMG utiliza inteligência artificial em julgamento virtual. 2018. Disponível em: http://www.tjmg.jus.br/portal-tjmg/noticias/tjmg-utiliza-inteligencia-artificial-em-julgamento-virtual.htm\#.W_VVmmhKjIX. Acesso em: 23 nov. 2018.

MOON, Jennifer A. A handbook of reflective and experiential learning. Theory and practice. London: RoutledgeFalmer, 2004.

PERNAMBUCO. Tribunal de Justiça de Pernambuco. TJPE usará inteligência artificial para agilizar processos de execução fiscal no Recife. 2018. Disponível em: http://www. tjpe.jus.br/agencia-de-noticias/noticias-em-destaque-com-foto/-/asset_publisher/Mx1aQA$\mathrm{V} 3 w f G N /$ content/tjpe-usara-inteligencia-artificial-para-agilizar-processos-de-execucao-fiscal-no-recife?inheritRedirect=false. Acesso em: 23 nov. 2018.

RODRIGUES, Horácio Wanderlei. Pensando o ensino do direito no século XXI: diretrizes curriculares, projeto pedagógico e outras questões pertinentes. Florianópolis: Fundação Boiteux, 2005.

RODRIGUES, Horácio Wanderlei. A crise do ensino jurídico de graduação no Brasil contemporâneo: indo além do senso comum. 1992. 397 f. Tese (Doutorado) - Universidade Federal de Santa Catarina. Florianópolis, 1992.

SUSSKIND, Richard. The End of Lawyers? Rethinking the Nature of Legal Services. Oxford: Oxford University Press, 2008.

THOMSON REUTERS. Artificial intelligence in law: The state of play 2016. Legal Executive Institute. 2016. 


\section{NOTA}

A pesquisa foi realizada de modo coletivo. As autoras participaram da condução e observação direta da experiência a qual foi analisada e relatada nesse artigo. $O$ aporte teórico foi trazido, especialmente, pela autora principal do artigo. Já a coautora pôde se debruçar mais sobre a escrita do relato prático da experiência e suas conclusões. As revisões e ajustes finais também foram feitos de modo sucessivo pelas autoras. 